\title{
Ferulic Acid Promotes Growth of Both Fast Glycolytic and Slow Oxidative Skeletal Muscles in Corticosteroid-Induced Rat Myopathy
}

\author{
SHEREEN M. SAMIR, M.D. and ABEER F. MOSTAFA, M.D. \\ The Department of Medical Physiology, Faculty of Medicine, Mansoura University, Egypt
}

\begin{abstract}
Background: Glucocorticoids (GCs) are wide spread antiinflammatory supplementation associated with various side effects especially in long term administration. Currently, there is no universally accepted prophylactic treatment for patients commencing long-term steroids.
\end{abstract}

Aim of Study: This research aims to study the possible beneficial role of Ferulic Acid (FA), as a naturally existing antioxidant and anti-inflammatory, in preventing muscle atrophy and promoting growth of fast glycolytic and slow oxidative skeletal muscle fibers in rat model of glucocorticoid induced myopathy.

Material and Methods: 48 rats were divided into 4 groups: Control, Ferulic acid supplemented group, Dexamethasone (Dex) supplemented group, rats supplemented with FA and Dex. After 2 weeks, all rats were sacrificed after taking blood samples. Left legs were preserved for histopathological and RT- PCR examinations. While, the right legs were kept for recording of isometric muscle contractility.

Results: Dex group showed marked decrease in muscle mass, isometric contraction forces, antioxidant enzymes and Mechano-Growth Factor (MGF) expression together with increase in myostatin expression and malondehyde. FA administration improved all these deleterious effects of Dex on both skeletal muscle fibers. This beneficial effect of FA was proved by histopathological improvement of sarcoplasmic degeneration, inflammatory cells infiltration and Zenker's necrosis of muscle bundle which featured rats' muscles of Dex group.

Conclusion: Ferulic acid, as an antioxidant and antiinflammatory, can be used as an adjuvant therapy with antiinflammatory corticosteroids to augment its therapeutic effect and reduce its myotrophic changes.

Key Words: Dexamethazone (Dex) - Ferulic Acid (FA) Myostatin - Mechano- growth factor $(M G F)-$ Fast glycolytic - Slow oxidative.

\section{Introduction}

GLUCOCORTICOIDS (GCs) are wide spread anti-inflammatory supplementation in several med-

Correspondence to: Dr. Shereen M.S. El-Sherbeiny, E-Mail: shereensamir2017@ hotmail.com ical conditions, such as rheumatoid arthritis, bronchial asthma, and myasthenia gravis. However, various side effects are associated with chronic administration of GCs especially in high doses [1] GC-induced myopathy is considered one of these serious side effects, whereas, majority of those patients suffer from proximal skeletal muscles weakness that are severe enough to interfere with their daily activities [2]. Previous experimental studies reported that fast-twitch skeletal muscle fiber atrophy caused by GC cannot exercise as expected due to aggravation of their overall disease status $[3,4]$. Thus, it is important to develop therapies for GC-induced myopathy that do not involve exercise.

GC has multiple pathophysiological mechanisms in inducing myopathy. One of these mechanisms is activation of Ubiquitin Proteasome System (UPS) which is the major cellular proteolytic systems by increasing MuRF1 and atrogin-1 in muscle proteolysis [5]. In addition, it is possible that GCinduced myopathy is related not only to muscle protein breakdown but also to angiogenesis by reducing Vascular Endothelial Growth Factor (VEGF) production that resulted in decrease in capillary number [6]. Also, Gupta and his college [7] suggested that a decrease in production of Insulin-like Growth Factor-1 (IGF-I) (stimulator of muscle mass development) together with an increase in production of myostatin (which inhibits muscle mass development) may be attributed to myopathy induced by glucocorticoids.

Ferulic acid (4-hydroxy-3-methoxycinnamic acid), one of biologically active substances presented in vegetables [8], fruits [9], and medicinal herbs [10]. Ferulic Acid (FA) is considered one of free radical scavengers [11] and an inhibitor of lipid peroxidation $[\mathbf{1 2 , 1 3}$. Ferulic acid, as a naturally existing antioxidant, has been a hot topic of research 
during recent years concerning human diseases and health [14]. Previous studies used as an antiinflammatory $[\mathbf{1 5 , 1 6}]$ and in treatment of diabetes [17], cardiovascular disease [18], cancer [19], and Alzheimer's disease [20]. It is also used as a food preservative [21] and as one of main components in sunscreens (UV protectant) and in skin lotions [22]. However, the role exerted by ferulic acid in the skeletal muscle growth has not been reported in any scientific researches. Currently, no safely accepted prophylactic medication for long-term steroids commencing patients. So, this research aims to study the possible beneficial role of FA in preventing muscle atrophy and promoting growth of fast glycolytic and slow oxidative skeletal muscle fibers in rat model of glucocorticoid induced myopathy.

\section{Material and Methods}

\section{Animals:}

Three-month-old male albino rats $(250-270 \mathrm{~g})$ were involved in this research. Animals were purchased from the Experimental Research Center (MERC) in Mansoura University, Egypt (period of the study: From 10 th August till 25 th August 2018). All rats were kept 2 or 3 per cage at 22$24^{\circ} \mathrm{C}$ with free access to food and water under a 12-h light/dark cycle. All experimental procedures had followed the Guidelines for Animal Experimentation of Institute for Laboratory Animal Research, National Research Council, Washington, DC and National Academy Press, no. 85-23, revised 1996 and with approval from our Local Committee of Animal Care and Use (approval number: R. 18.11.327).

\section{Chemicals:}

Dexamethazone (Dex) and Ferulic Acid (FA) were obtained from Sigma, Aldrich, USA. KrebsRinger bicarbonate buffer solution components were purchased from El-Gomhorria Company, Egypt, [NaCl: $122 \mathrm{mmol} / \mathrm{L}, \mathrm{NaHCO}_{3}: 25 \mathrm{mmol} / \mathrm{L}$, $\mathrm{KCl}: 2.8 \mathrm{mmol} / \mathrm{L}, \mathrm{KH} 2 \mathrm{PO} 4: 1.2 \mathrm{mmol} / \mathrm{L}, \mathrm{MgSO} 4$ $1.2 \mathrm{mmol} / \mathrm{L}, \mathrm{CaCl}_{2}: 1.3 \mathrm{mmol} / \mathrm{L}$ and glucose: $5 \mathrm{mmol}$ $/ \mathrm{L}]$.

\section{Experimental design:}

48 rats were used and randomly divided in this experiment into 4 groups ( $\mathrm{n}=12$ for each group): Gp. (C): Control, gp. (FA): Ferulic acid supplemented group, gp. (Dex): Dexamethasone supplemented group, gp. (Dex + FA): Rats supplemented with FA and dexamethasone. Rats in the Dex and Dex + FA groups were subcutaneously injected with $2 \mathrm{mg} / \mathrm{kg}$ dexamethasone (Dex) 6 days per week for 2 weeks [23]. In addition to Dex injection, rats in the FA and Dex + FA groups were treated by intragastric administration of $50 \mathrm{mg} / \mathrm{kg} /$ day ferulic acid [24], while rats in the control and FA groups were injected with saline instead of Dex for the same time period as the Dex group.

\section{Sample preparation:}

After weighing rats and collecting blood samples at the end of experimental study ( 2 weeks), they were decapitated under $4 \%$ isoflurane inhalation anesthesia. The bilateral fast glycolytic Tibialis Anterior (TA) and Slow Oxidative Soleus (SOL) muscles [25] were extracted. Part of each extracted muscle from the left leg was immediately kept in liquid nitrogen at $-80^{\circ} \mathrm{C}$ for determination of myostatin and Mechano-Growth Factor (MGF) levels. While, the remaining part was soaked in neutral formalin $10 \%$ for histopathological examination.

\section{Force measurements:}

Removal of the right leg was done by femur transection. Then, immediately placing the leg into a Krebs buffer in a polycarbonate chamber, at $\mathrm{pH}$ 7.4, constant $95 \% \mathrm{O}_{2}$ and $5 \% \mathrm{CO} 2$ and maintained at $35^{\circ} \mathrm{C}$. The origin of TA and SOL muscles were kept intact to avoid excess muscle damage. Horizontal positioning of the leg with fixating it by metal hooks to the chamber bottom. Direct electrical stimulations were done using Biopac Student Lab (BIOPAC Systems Inc., CA, USA) with a stimulator (Biopac student isolaton stimulator module; includes AC 100A power), force transducer assembly (SS121LA; includes an S hook) and tension adjuster (HDW100A). Positioning of the force transducer arm was performed in which the muscle were at a $90^{\circ}$ angle to the leg. In all experiments, the muscles were mounted at optimal length for maximum isometric twitch force measurment. Muscle contractions were recorded using field stimulations through two platinum plate electrodes applying supramaximal currents of $0.2 \mathrm{msec}$ duration. In order to obtain the optimal muscle length and the voltage of supramaximal stimulation, micro-manipulations of muscle length and a series of twitch contractions ( $1 \mathrm{~Hz}$ square wave pulse) were done, rest the muscle for at least $30 \mathrm{~s}$ between twitch responses until twitch tension was maximal [26]. The optimal muscle length (Lo) could be defined as the length needed to generate the maximal twitch force and it is recorded with a digital caliper. Supra-maximal stimulation is the minimum amount of current needed in order to ensure recruitment of all muscle fibers with a single action potential. Recording of the isometric muscle contraction, in $\mathrm{g}$ tension, was done at the end of stimulations of the muscle. The speed of the contractile properties 
was determined by recording the time to peak twitch tension and the time taken to reach 50\% relaxation.

\section{Establish frequency -force relationship:}

The frequency-force relationship could be established after achievement of Lo by stimulating the muscle using grading frequencies $10,30,50$, $80,100,120,150,180,200$, and $250 \mathrm{~Hz}$. The muscle was rested for $3-5 \mathrm{~min}$ between successive stimuli and stimulation was delivered for a period of 500$900 \mathrm{msec}$. The plateau of the frequency-force relationship was used to determine the maximum absolute isometric tetanic force (Po). Po for TA muscle was typically achieved with $110 \mathrm{~Hz}$, and for soleus muscles with $100 \mathrm{~Hz}$. Then, for recording the strength of muscle contraction after recovery, the muscle was kept in an organ path for $5 \mathrm{~min}$ to recover from fatigue after tetanic stimulation before the application of a single supramaximal stimulus.

\section{Maximum isometric tetanic force:}

Muscles were typically stimulated 2-3 times with rest periods of 3-5 minutes in order to determine optimum force generation using supramaximal voltage at Lo with a plateau stimulation frequency.

Measurement of muscle weight and cross sectional area:

After recording the muscle contraction, the muscles were detached and the tendons of both proximal and distal ends were cut. Then the muscles were dry with wipes twice to measure the muscle weight. Calculate the muscle cross-sectional area was calculated by using the following equation; cross-sectional area $=($ Muscle mass, in gram $) /$ $\left[1.06 \mathrm{~g} / \mathrm{cm}^{3} \mathrm{X}\right.$ (optimal fiber length, in $\mathrm{cm}$ )]. Where $1.06 \mathrm{~g} / \mathrm{cm}^{3}$ is the muscle density.

Also, the optimal fiber length was calculated as 0.6 or $0.71 \mathrm{X}$ Lo. Where 0.6 represents the ratio of the fiber length to the Lo of tibialis anterior muscle and 0.71 represents the ratio of fiber length to the Lo of soleus muscle [27].

\section{Specific force calculations:}

Po values are normalized for cross sectional area as absolute Po is dependent upon muscle size so, specific force ( $\mathrm{sPo}$ ) in $\mathrm{gm} / \mathrm{m}^{2}$ was determined by dividing Po by the calculated total muscle crosssectional area.

\section{Real-time PCR:}

Total RNA was extracted from muscle tissues (TA and SOL) according to Chomczynski and Sacchi method [28], the concentration of which was measured in a Genespec spectophotometer (Shimatzu). Roche Diagnostics kit was used for synthesis of first strand cDNA. Specific primers for myostatin, Mechano-Growth Factor (MGF) and GAPDH (as external control) were then used for the detection of the expression of these transcripts by real-time RT-PCR (Table 1). Myostatin, MGF and reference gene PCR amplifications for each muscle were performed simultaneously for each individual animal. The template DNA was replaced with PCR-grade water in each run as a negative control. A light cycler machine (Roche Diagnostics) was used to detecting and quantifying the newly synthesized DNA, also for verification of product authenticity using the in-built melting curve analysis procedure and values were expressed as myostatin or MGF/reference gene ratios.

Table (1): Primers for real-time RT-PCR.

\begin{tabular}{lll}
\hline mRNA & \multicolumn{1}{c}{ Sense Primer } & \multicolumn{1}{c}{ Antisense Primer } \\
\hline Myostatin & TGCTGTAACCTTCCCAGGACCA & GTGAGGGGGTAGCGACAGCAC \\
GAPDH & CCATTCTTCCACCTTTGATGCT & TGTTGCTGTAGCCATATTCATTGT \\
MGF & GGAGGCTGGAGATGTACTGTGCT & TCCTTTGCAGCTTCCTTTCTTG \\
\hline
\end{tabular}

MGF: Mechano-Growth Factor.

\section{Detection of plasma oxidative stress markers:}

The plasma levels of Malondialdehyde (MDA) and antioxidant enzymes including GSH, CAT and SOD were detected according to the manufacturer's instructions by using colorimetric kits (BioDiagnostics, Dokki, Giza, Egypt).

\section{Histopathological examination:}

Parts of TA and SOL of left legs were placed in $10 \%$ neutral formalin then fixed in paraffin blocks. Sections of $5 \mathrm{gm}$ thickness were cut from paraffin blocks to be processed for routine hematoxylin and eosin staining (longitudinal and transverse sections). Slides were examined blindly by histopathological expert.

\section{Statistical analysis:}

The SPSS software (Ver. 19.0, IBM, Chicago, IL, USA) was used for analysis of the data that were collected from repeated experiments. Statistically significant differences between groups were performed by one-way analysis of variance (ANO- 
VA) that was followed by Tukey's post hoc test. All data are presented as mean \pm SD and $p$-values less than 0.05 were considered statistically significant.

\section{Results}

Tables $(2,3)$ show that there were significant reduction in muscle mass, Lo and cross-sectional area of both soleus and tibialis anterior of Dex group as compared with those of the other groups. We noticed also that administration of FA improved the state of muscle in rats with and without dexamethazone supplementation as compared to control or Dex group.

Regarding the isometric contractile properties in soleus muscle, Table (4) and Fig. (1) showed significant reduction in maximum isometric twitch force, tetanic force and specific force together with significant elongation in time to peak twitch and half relaxation time in Dexamethazone supplemented rats as compared to either control or FA groups. These previous changes were improved significantly with supplementation of FA in Dex treated rats. Moreover, FA in normal rats showed nearly normal contractile times and significant increase in maximum isometric tetanic force and specific force as compared to control group.

As regards to tibialis anterior muscle, Table (5) and Fig. (2) showed significant reduction in force of contractions either twitches, tetanic or specific together with significant elongation in measured twitch times in Dex group as compared to either control or FA groups. These deteriorations were improved significantly with supplementation of FA in Dex + FA group. Interestingly, normal rats treated with FA showed significant powerful contractile forces with reduction in twitch times when compared to control group.

Table (6) represented the oxidative stress markers in rat serum that showed significant elevation in MDA together with significant reduction in SOD, CAT and GSH in Dex group as compared to normal control and FA groups. These markers were improved with FA supplementation in Dex + FA group. Although FA in normal rats showed nearly normal values in most oxidative markers, there was significant increase in CAT level as compared to control group.

Regarding to results of RT-PCR expression for MGF and myostatin in both tibialis anterior and soleus muscles in all experimental groups, Figs. $(3,4)$ represented significant decrease in MGF and increase in myostatin expression in Dex group as compared to control one. While, muscles of Dex + FA rats showed significant improvement in expression of both factors especially in tibialis anterior muscle as compared to Dex group results. Moreover, FA rats expressed MGF in a significant higher level together with decrease in myostatin expression especially in tibialis anterior muscle when compared to control results.

Histopathological examination of rat skeletal muscles in FA group Fig. (6) showed normal parallel skeletal muscle fibers with peripheral nucleus in both tibialis anterior and soleus which were similar to the control skeletal muscles sections.

Histopathological results of tibialis anterior Fig. (7A,B) alleviated that Dex group showed sarcoplasmic degeneration associated with loss of striation and increase the interstitial cells with Zenker's necrosis of some muscle bundle which separated with hollow zone. Moreover, histopathological examination of soleus muscle Fig. (7C,D) showed Zenker's necrosis of some muscle bundle associated with inflammatory cells infiltration and interstitial cells hyperplasia in Dex group.

Fig. (8) showed histopathological examination of rat skeletal muscles in Dex + FA group. Fig. $(8 \mathrm{~A}, \mathrm{~B})$ showed that tibialis anterior represented with mild degree of sarcoplasmic eosinophilia with limited sarcoplasmic degeneration within few bundles. While in soleus muscle Fig. (8C,D) showed mild degree of myolysis with normal nucleus.

Table (2): General properties of the soleus muscle in all experimental groups.

\begin{tabular}{lllll}
\hline & \multicolumn{1}{c}{ C } & \multicolumn{1}{c}{ FA } & \multicolumn{1}{c}{ Dex } & \multicolumn{1}{c}{ Dex + FA } \\
\hline Muscle mass $(\mathrm{g})$ & $0.138 \pm 0.03$ & $0.169 \pm 0.08 *$ & $0.082 \pm 0.004 * \$$ & $0.117 \pm 0.02 \# \$$ \\
Optimal muscle length $(\mathrm{cm})$ & $1.02 \pm 0.08$ & $1.25 \pm 0.03$ & $0.83 \pm 0.05 * \$$ & $0.98 \pm 0.06 \# \$$ \\
Cross-sectional area $\left(\mathrm{cm}^{2}\right)$ & $0.18 \pm 0.004$ & $0.23 \pm 0.001 *$ & $0.13 \pm 0.001 * \$$ & $0.17 \pm 0.003 \# \$$ \\
\hline
\end{tabular}

Test used: One way ANOVA followed by post-hoc tukey.

Values are expressed as means $\pm \mathrm{SD}$.

C : Control group.

FA : Ferulic Acid supplemented group.

Dex : Dexamethasone supplemented group.

Dex + FA : Dexamethasone and ferulic acid supplemented group

*: Significantly different from control group.

\$: Significantly different from FA group.

\#: Significantly different from Dex group. 
Table (3): General properties of the tibialis anterior muscle in all experimental groups.

\begin{tabular}{lllll}
\hline & \multicolumn{1}{c}{ C } & \multicolumn{1}{c}{ FA } & \multicolumn{1}{c}{ Dex } & \multicolumn{1}{c}{ Dex + FA } \\
\hline Muscle mass $(\mathrm{g})$ & $0.390 \pm 0.01$ & $0.477 \pm 0.03 *$ & $0.148 \pm 0.05 * \$$ & $0.284 \pm 0.04 \# \$$ \\
Optimal muscle length $(\mathrm{cm})$ & $1.79 \pm 0.03$ & $1.81 \pm 0.06$ & $0.97 \pm 0.04 * \$$ & $1.37 \pm 0.06 \#$ \\
Cross-sectional area $\left(\mathrm{cm}^{2}\right)$ & $0.33 \pm 0.002$ & $0.42 \pm 0.009 *$ & $0.20 \pm 0.005 * \$$ & $0.30 \pm 0.007 \# \$$ \\
\hline
\end{tabular}

Test used: One way ANOVA followed by post-hoc tukey.

Values are expressed as means \pm SD.

$\mathrm{C} \quad$ : Control group.

FA : Ferulic Acid supplemented group.

Dex : Dexamethasone supplemented group.

Dex + FA : Dexamethasone and ferulic acid supplemented group

*: Significantly different from control group.

$\$$ : Significantly different from FA group.

\#: Significantly different from Dex group.

Table (4): Isometric contractile properties of the soleus muscle in different experimental groups.

\begin{tabular}{lllll}
\hline & \multicolumn{1}{c}{ C } & \multicolumn{1}{c}{ FA } & \multicolumn{1}{c}{ Dex } & \multicolumn{1}{c}{ Dex + FA } \\
\hline Time to peak twitch $(\mathrm{sec})$ & $0.035 \pm 0.006$ & $0.031 \pm 0.004$ & $0.55 \pm 0.06 * \$$ & $0.13 \pm 0.07 * \# \$$ \\
Half relaxation time $(\mathrm{sec})$ & $0.15 \pm 0.03$ & $0.13 \pm 0.02$ & $0.63 \pm 0.05 * \$$ & $0.42 \pm 0.02 * \# \$$ \\
Max. isometric twitch force $(\mathrm{g})$ & $4.8 \pm 0.2$ & $5.3 \pm 0.4$ & $2.3 \pm 0.12 * \$$ & $4.1 \pm 0.2 \# \$$ \\
Max. isometric tetanic force $(\mathrm{g})$ & $9.7 \pm 0.4$ & $23.3 \pm 1.2 *$ & $5.6 \pm 0.3 * \$$ & $9.1 \pm 0.6 \# \$$ \\
Specific force $\left(\mathrm{gm} / \mathrm{m}^{2}\right)$ & $53.9 \pm 2.7$ & $80.3 \pm 4.2 *$ & $43.1 \pm 2.3 * \$$ & $53.5 \pm 3.07 \# \$$ \\
Force after tetanic contraction $(\mathrm{g})$ & $3.4 \pm 0.1$ & $3.9 \pm 0.6$ & $1.04 \pm 0.02 * \$$ & $1.5 \pm 0.09 * \# \$$ \\
\hline
\end{tabular}

Test used: One way ANOVA followed by post-hoc tukey.

Values are expressed as means \pm SD.

C : Control group.

FA : Ferulic Acid supplemented group.

Dex : Dexamethasone supplemented group.

Dex + FA : Dexamethasone and ferulic acid supplemented group.

*: Significantly different from control group.

$\$$ : Significantly different from FA group.

\#: Significantly different from Dex group.

Table (5): Isometric contractile properties of the tibialis anterior muscle in different experimental groups.

\begin{tabular}{lllll}
\hline & \multicolumn{1}{c}{ C } & \multicolumn{1}{c}{ FA } & \multicolumn{1}{c}{ Dex } & \multicolumn{1}{c}{ Dex + FA } \\
\hline Time to peak twitch $(\mathrm{sec})$ & $0.015 \pm 0.003$ & $0.01 \pm 0.001 *$ & $0.35 \pm 0.08^{*} \$$ & $0.11 \pm 0.06 * \# \$$ \\
Half relaxation time $(\mathrm{sec})$ & $0.09 \pm 0.008$ & $0.07 \pm 0.005^{*}$ & $0.22 \pm 0.09 * \$$ & $0.13 \pm 0.04 * \# \$$ \\
Max. isometric twitch force $(\mathrm{g})$ & $8.5 \pm 1.1$ & $10.2 \pm 1.5^{*}$ & $5.8 \pm 1.1 * \$$ & $7.8 \pm 1.6 \# \$$ \\
Max. isometric tetanic force $(\mathrm{g})$ & $11.3 \pm 1.3$ & $18.9 \pm 3.1 *$ & $6.6 \pm 1.08 * \$$ & $10.7 \pm 2.01 \# \$$ \\
Specific force $\left(\mathrm{gm} / \mathrm{m}^{2}\right)$ & $34.2 \pm 4.02$ & $49.7 \pm 6.5 *$ & $28.7 \pm 3.2 * \$$ & $33.4 \pm 3.9 \# \$$ \\
Force after tetanic contraction $(\mathrm{g})$ & $3.3 \pm 0.3$ & $2.8 \pm 0.5$ & $0.03 \pm 0.005 * \$$ & $1.6 \pm 0.3 * \# \$$ \\
\hline
\end{tabular}

Test used: One way ANOVA followed by post-hoc tukey.

Values are expressed as means \pm SD.

C : Control group.

FA : Ferulic Acid supplemented group.

Dex : Dexamethasone supplemented group

Dex + FA : Dexamethasone and ferulic acid supplemented group

*: Significantly different from control group.

$\$$ : Significantly different from FA group.

\#: Significantly different from Dex group.

Table (6): Serum levels of oxidative stress markers in different experimental groups.

\begin{tabular}{lllll}
\hline & \multicolumn{1}{c}{ C } & \multicolumn{1}{c}{ FA } & \multicolumn{1}{c}{ Dex } & \multicolumn{1}{c}{ Dex + FA } \\
\hline MDA $(\mathrm{nmol} / \mathrm{mL})$ & $2.13 \pm 0.11$ & $2.33 \pm 0.004$ & $8.11 \pm 0.23 * \$$ & $4.31 \pm 0.07 * \# \$$ \\
SOD $(\mathrm{U} / \mathrm{mL})$ & $91.42 \pm 2.56$ & $99.12 \pm 5.31$ & $23.45 \pm 1.05^{*} \$$ & $46.62 \pm 3.12^{*} \$$ \\
$\mathrm{CAT}(\mathrm{U} / \mathrm{L})$ & $4.53 \pm 0.07$ & $5.23 \pm 1.6^{*}$ & $0.92 \pm 1.1 * \$$ & $3.79 \pm 1.9 * \# \$$ \\
GSH $(\mathrm{mg} / \mathrm{dL})$ & $32.47 \pm 2.5$ & $37.83 \pm 3.2$ & $15.68 \pm 0.54 * \$$ & $25.37 \pm 2.4 * \# \$$ \\
\hline
\end{tabular}

Test used: One way ANOVA followed by post-hoc tukey.

Values are expressed as means \pm SD.

C : Control group.

FA : Ferulic Acid supplemented group.

Dex : Dexamethasone supplemented group.

Dex + FA : Dexamethasone and ferulic acid supplemented group.

*: Significantly different from control group.

$\$$ : Significantly different from FA group.

\#: Significantly different from Dex group. 
(a)
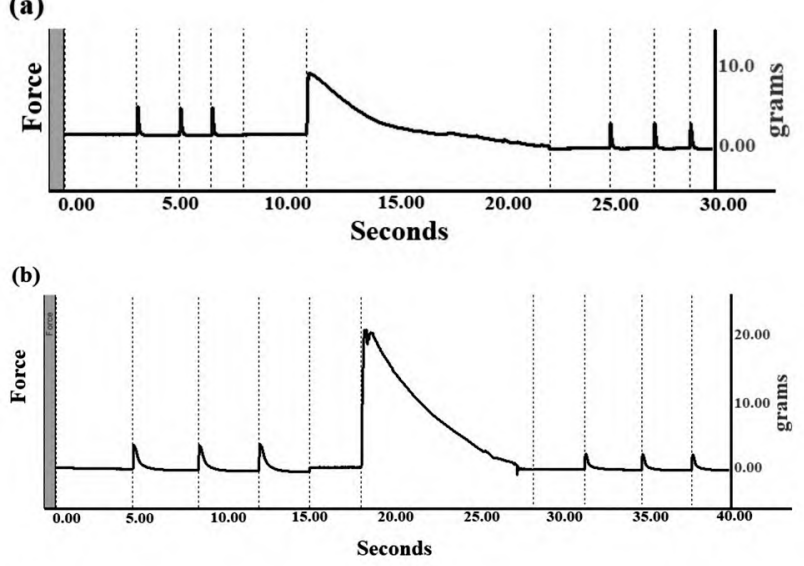

(c)

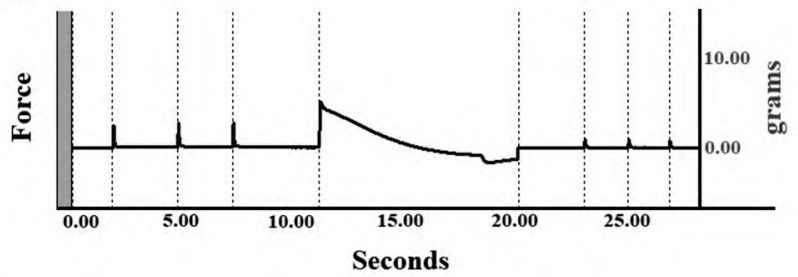

(d)



Fig. (1): Contractile properties of rat soleus muscle in different experimental groups. (A) Control gp. (B) FA gp. (C) Dex gp. (D) Dex + FA gp.

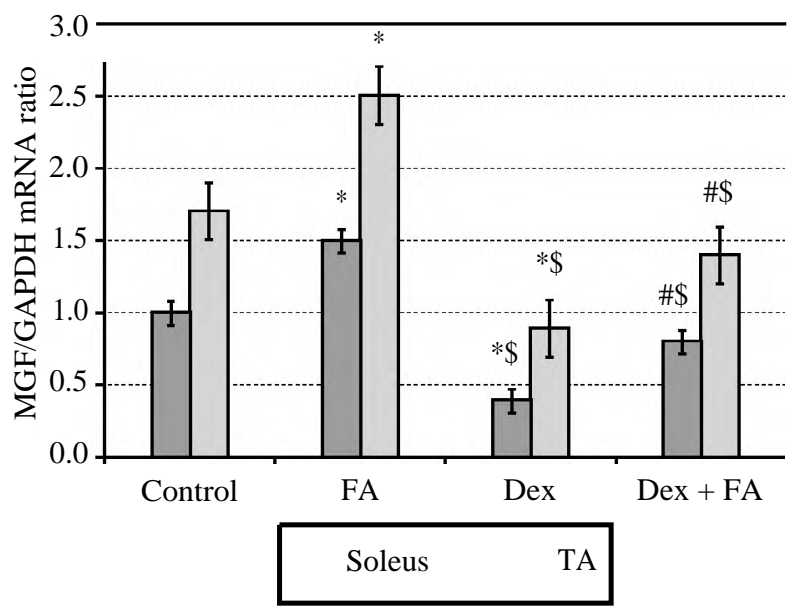

Fig. (3): Quantification of MGF mRNA levels in soleus and Tibialis Anterior (TA) muscles of different experimental groups.

Test used: One way ANOVA followed by post-hoc tukey.

Values are expressed as means $\pm \mathrm{SD}$.

*: Significantly different from control group.

$\$$ : Significantly different from FA group.

\#: Significantly different from Dex group.
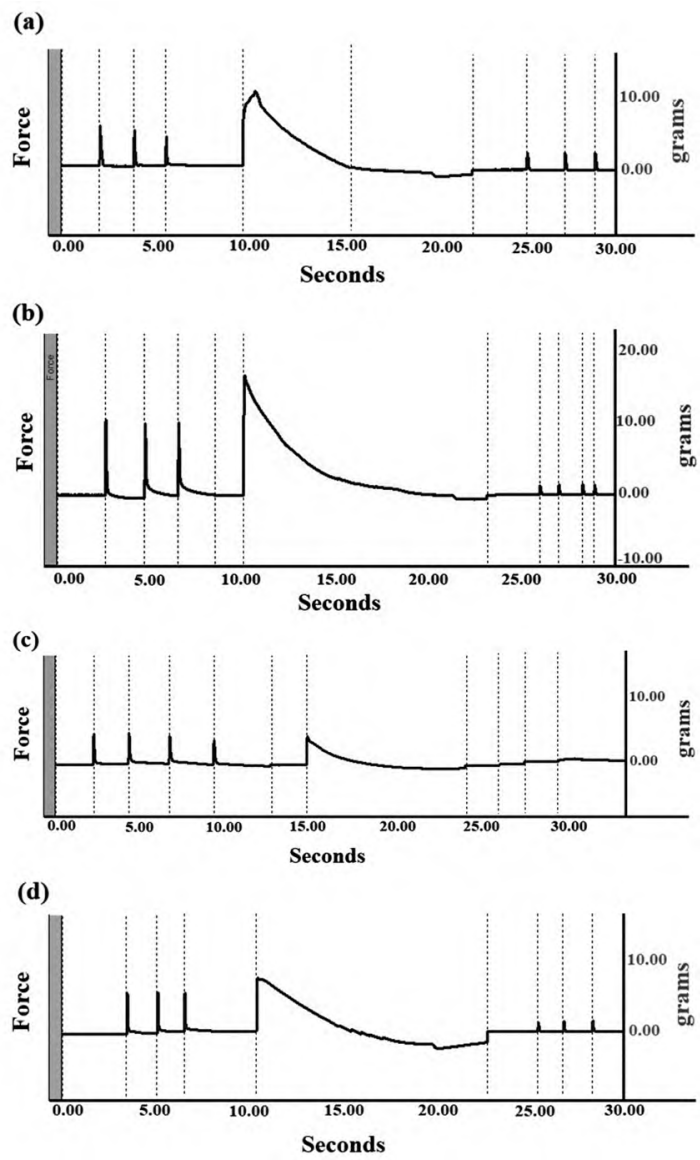

Fig. (2): Contractile properties of rat tibialis anterior muscle in different experimental groups. (A) Control gp. (B) FA gp. (C) Dex gp. (D) Dex + FA gp.

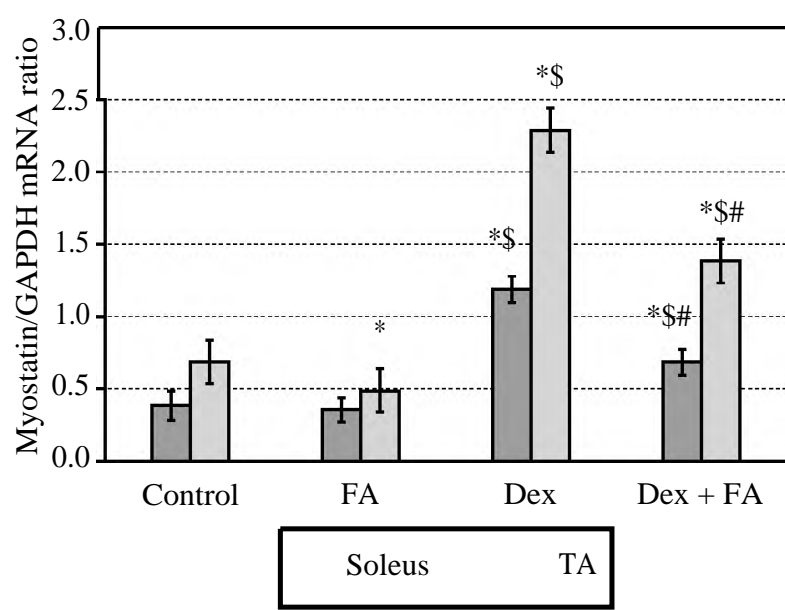

Fig. (4): Quantification of myostatin mRNA levels in soleus and Tibialis Anterior (TA) muscles of different experimental groups.

Test used: One way ANOVA followed by post-hoc tukey.

Values are expressed as means \pm SD.

*: Significantly different from control group.

$\$$ : Significantly different from FA group.

\#: Significantly different from Dex group. 


\section{Control group}
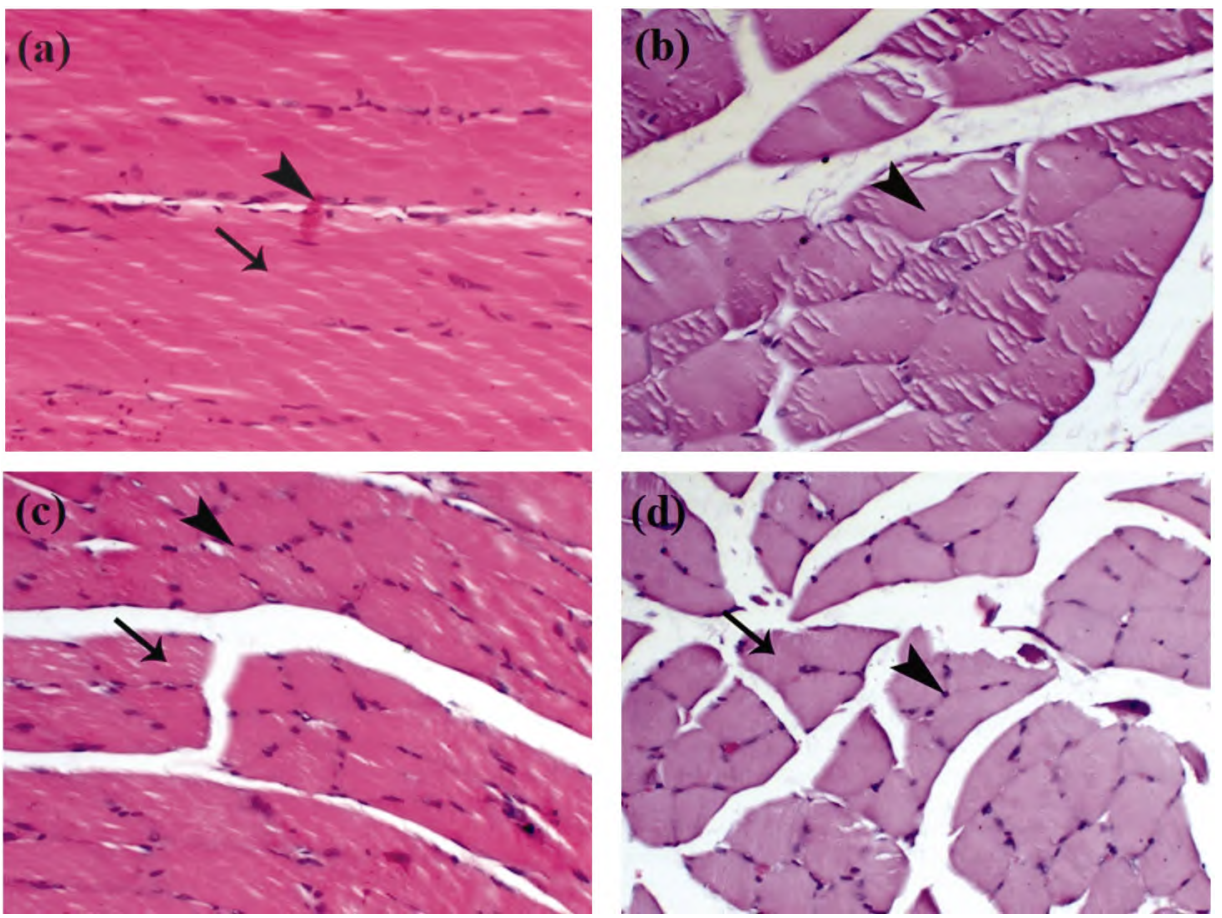

Fig. (5): Histopathological examination of skeletal muscles in control group (H \& E, X200). (A) Longitudinal section of tibialis anterior muscle showing normal parallel skeletal muscle fibers (arrow) with peripheral nucleus (arrowhead), (B) Transverse section of tibialis anterior muscle showing normal cross round to polygonal muscle fibers (arrowhead) with peripherally-located nucleus, (C) Longitudinal section of soleus muscle showing normal parallel skeletal muscle fibers (arrow) with peripheral nucleus (arrowhead), (D) Transverse section of soleus muscle showing normal cross round to polygonal muscle fibers (arrowhead) with peripherally-located nucleus (arrowhead).

\section{FA group}
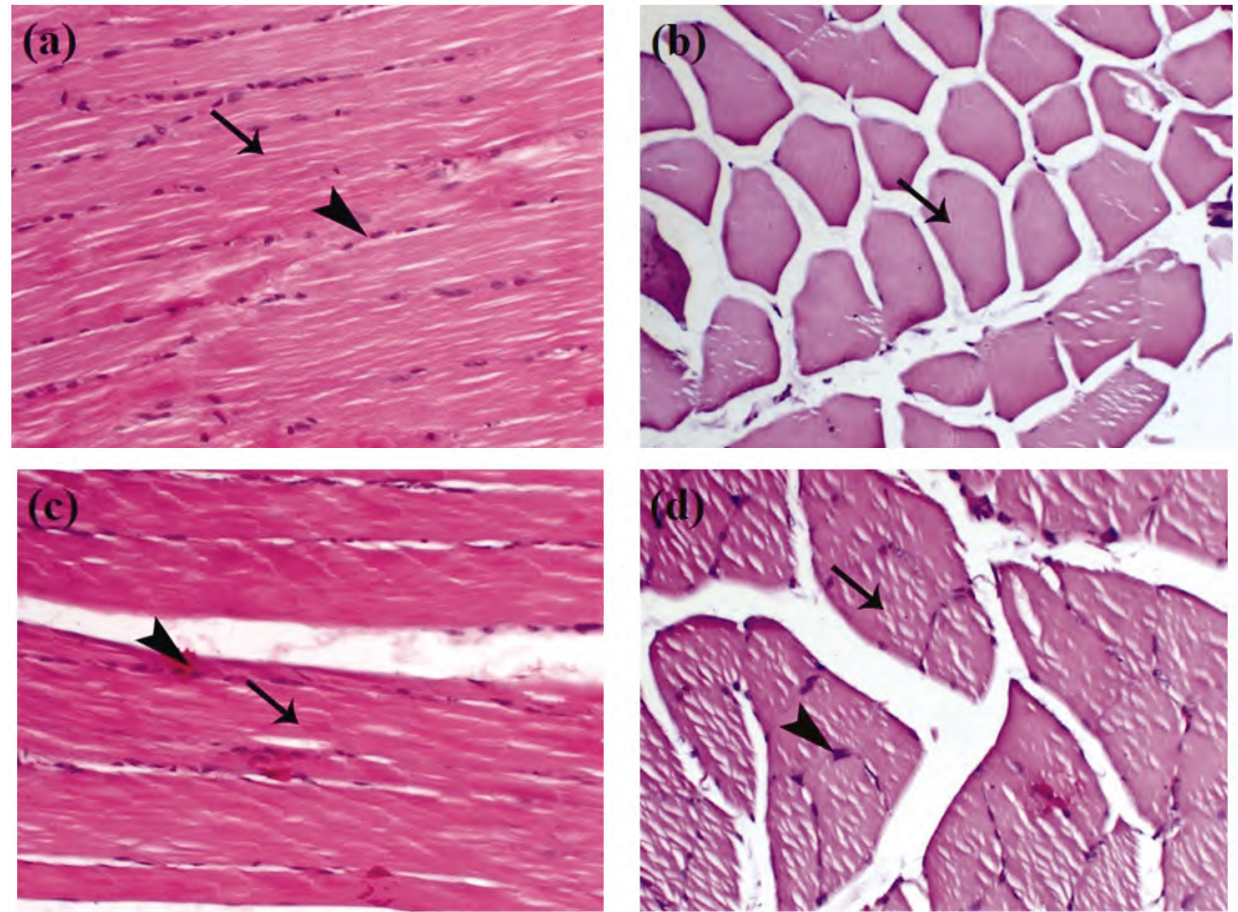

Fig. (6): Histopathological examination of skeletal muscles in FA group (H \& E, X200). (A) Longitudinal section of tibialis anterior muscle showing normal parallel skeletal muscle fibers (arrow) with peripheral nucleus (arrowhead), (B) Transverse section of tibialis anterior muscle showing normal cross round to polygonal muscle fibers (arrowhead) with peripherally-located nucleus, (C) Longitudinal section of soleus muscle showing normal parallel skeletal muscle fibers (arrow) with peripheral nucleus (arrowhead), (D) Transverse section of soleus muscle showing normal cross round to polygonal muscle fibers (arrowhead) with peripherally-located nucleus (arrowhead). 

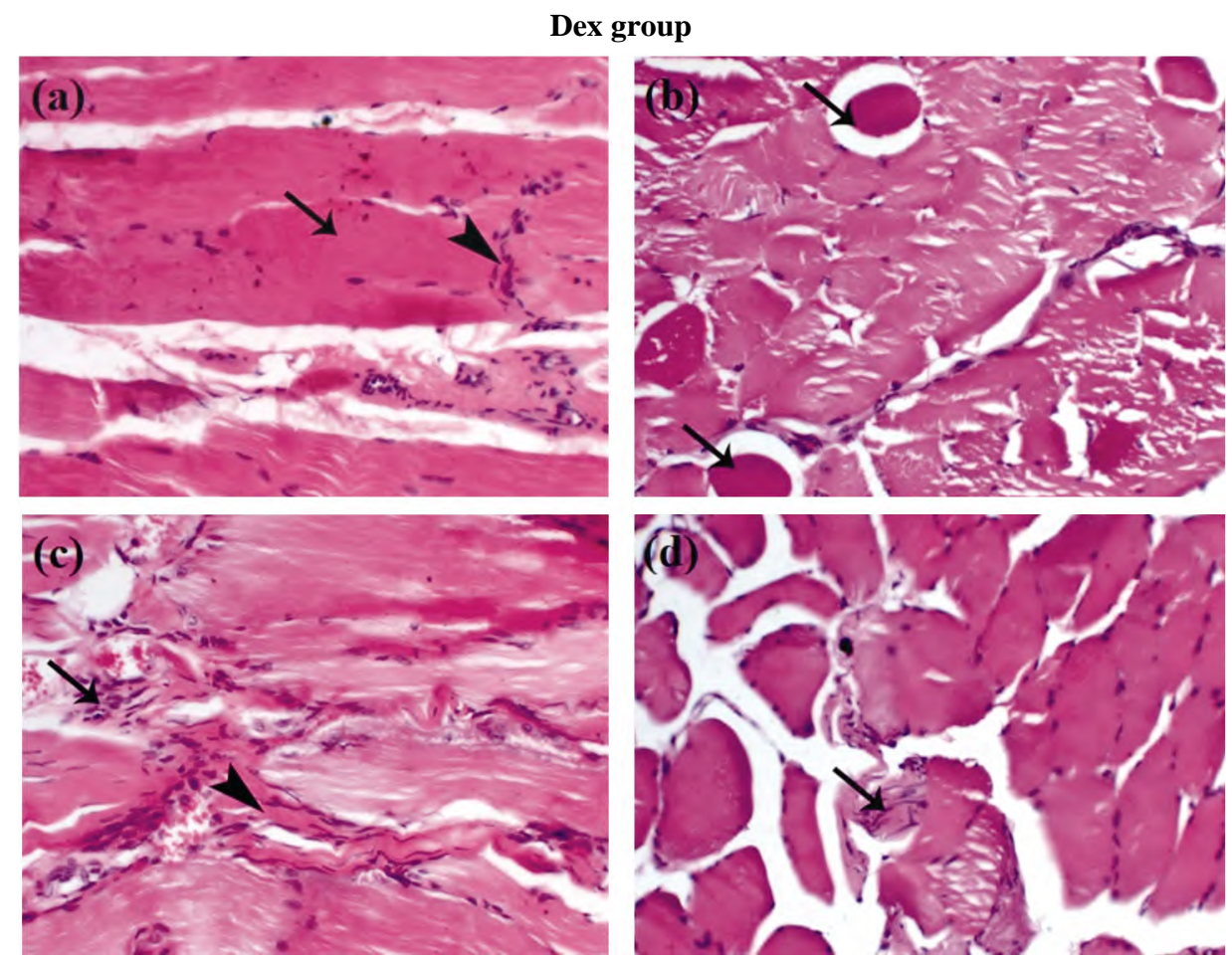

Fig. (7): Histopathological examination of skeletal muscles in Dex group (H \& E, X200). (A) Longitudinal section of tibialis anterior muscle showing sarcoplasmic degeneration associated with loss of striation (arrow) and increase the interstitial cells (arrowhead), (B) Transverse section of tibialis anterior muscle showing Zenker's necrosis of some muscle bundle which separated with hollow zone (arrows), (C) Longitudinal section of soleus muscle showing Zenker's necrosis (arrowhead) associated with inflammatory cells infiltration and interstitial cells hyperplasia (arrowhead), (D) Transverse section of soleus muscle showing Zenker's necrosis of some muscle bundle (arrow).
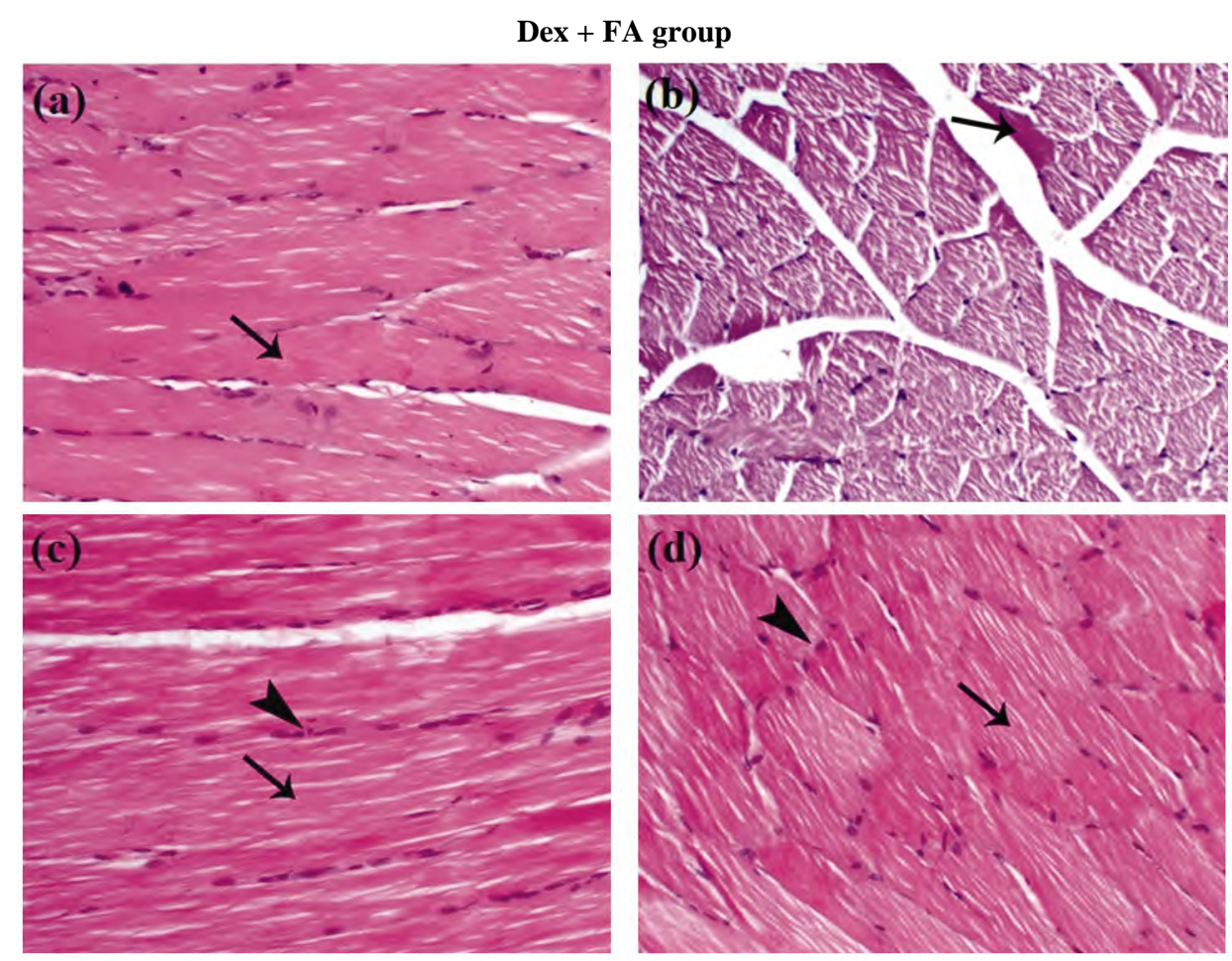

Fig. (8): Histopathological examination of skeletal muscles in Dex + FA group (H \& E, X200). (A) Longitudinal section of tibialis anterior muscle showing mild degree of sarcoplasmic eosinophilia (arrow), (B) Transverse section of tibialis anterior muscle showing limited sarcoplasmic degeneration within few bundles (arrow), (C) Longitudinal section of soleus muscle showing mild degree of myolysis (arrow) with normal nucleus (arrowhead), (D) Transverse section of soleus muscle showing mild degree of myolysis (arrow) with normal nucleus (arrowhead). 


\section{Discussion}

Several synthetic glucocorticoids are the most popular anti-inflammatory and immunosuppressive medication utilized with several medical and surgical problems. Although they have therapeutic benefits but their administration for a long period has often resulted in many serious side effects like progressive muscle weakness and steroid myopathy. According to Morimoto et al., [23] experimental study in rats, 2 weeks of dexamethazone administration has been reported to be an enough period for inducing skeletal muscle fiber atrophy in rats. Thus, rats injected with Dex are considered to be a suitable model for corticosteroid-induced myopathy.

In this study, the deleterious effect of dexamethasone administration for such period was detected by significant decrease in muscle mass with percentage of change from normal ones equal $27.8 \%$ for soleus muscle and $39.4 \%$ for tibialis anterior muscle. Moreover, there was dramatic decrease in cross sectional area of both muscles with percentage of decrease equal $43 \%$ and $62 \%$ for SOL and TA respectively. These results are in consistent with results of Risson et al., [29] and Schakman et al., [2], that showed the effect of dexamethasone was strongly affect the fast-twitch muscle fibers more than the slow-twitch muscle fibers and demonstrated more severe atrophy in type IIb fibers than type I fibers. These observed differences in the degree of atrophy between both types of muscle fibers could be explained as Shimizu et al., 2011 study that found difference in distribution of the corticosteroid receptor; with greater expression in fasttwitch muscle fibers than in slow-twitch muscle fibers.

Ferulic acid is a widely distributed and natural existing antioxidant and anti-inflammatory polyphenol that founded in free and bound forms in many vegetables, fruits, and cereal grains. We aimed in this research to study its possible protective effect on corticosteroid-induced muscle atrophy. So, our results revealed that rats supplied with both Dex and FA showed significant improvement in their muscle mass with percentage of improvement equal $30 \%$ for SOL and $46 \%$ for TA. Together with increase in cross sectional area than those of rats supplied with Dex only by a percentage of increase equal 24\% for SOL and 33\% for TA. Administration of FA in normal control rats resulted in significant increase in both muscles masses as compared to normal control ones as well as the cross sectional areas were increased by $18 \%$ in SOL and $21 \%$ in
TA. These results found that FA has hypertrophic effect on both types of muscle fibers.

Our results revealed significant prolongation in time of contraction and relaxation together with decrease in forces of contraction in TA and SOL of rats supplemented with Dex as compared with control ones. These contractile effects could be understood by the associating increase in MDA and decrease in antioxidant enzymes (SOD, CAT, GSH) which is reflected on the muscle mass causing significant atrophy with decreasing the expression of growth factor (MGF) and increasing the expression of myostatin. FA either alone or combined with Dex showed marked improvement in the contractile properties of both TA and SOL muscles especially the absolute and specific tetanic forces. Checking the accuracy and validity of values for absolute and specific forces is very important in evaluating the efficacy of any treatment used for improving functional shortage associated with muscular dystrophy. The favorable contractile effect of FA on both fast glycolytic and slow oxidative skeletal muscles are believed to be mediated by decreasing oxidative stress during contraction and enhancing the expression of growth factor (MGF).

Previous studies have suggested that the harmful effects of oxidative stress may be through its key role in the pathogenesis of endothelial dysfunction $[30,31]$. Yin [32] and his coworkers proved that the protective effect of ferulic acid against vascular endothelial dysfunction was through the NF- icB pathway involving increase in nitric oxide and endothelial nitric oxide synthase enzyme levels.

Myostatin, a member of the transforming growth factor- 0 (TGF- 0 ) superfamily, is a negative regulator of muscle growth. Previous studies demonestrated that myostatin inhibits protein synthesis and myoblast proliferation and differentiation during myogenesis [33], as well as activating proteolytic pathways [34]. Myostatin overexpression causes skeletal muscle atrophy in mammals [35] In contrast, mutation or genetic ablation of the myostatin gene induces hypertrophy of mammalian skeletal muscle [36]. Furthermore, it was reported that myostatin inhibition increases skeletal muscle mass and strength in both adult and aged animals $[37,38]$. The elevation of myostatin levels detected in Dex group as compared to control one are in accordance with the known functional role of myostatin, i.e., the suppressing effects on proliferation and differentiation of myoblasts. However, FA administration either alone or combined with Dex was associated with decreased expression of 
myostatin which was reflected physically on the muscle mass and cross sectional area as well as physiologically on the isometric contractile forces in a positive manner.

On the other hand, IGF-I is a positive regulator of skeletal muscle growth. Different splice variants of IGF-I are expressed in muscle tissue, and the most specific variant is IGF-IEb (mechano-growth factor; MGF) which thought to be expressed mostly as a local growth factor in skeletal muscle [39] The elevation of MGF level indicates increase in protein synthesis and satellite cells proliferation and differentiation [40]. Also, exogenously infused IGF-1 restores satellite cell proliferative potential of old immobilized skeletal muscle [41]. Moreover, the significant decrease in of MGF level with aging may partially responsible for the decrease in satellite cells proliferative capacity with ageing.

Our results indicated muscle atrophy and decrease muscle mass in rats of Dex group proved by significant decrease in MGF expression in both muscles as compared to control group. This decrement in Dex group was improved significantly by co-administration of FA which indicates its trophic effect that antagonizes the harmful Dex effect on both fast and slow types of muscles. Furthermore, FA alone showed marked increase in MGF expression as compared to control rats that highlight its beneficial trophic effect on both muscle fibers in a significant manner.

The present results were proved by histopathological examination of skeletal muscles that revealed degenerative changes in tibialis anterior and soleus muscles of rats in Dex group. These changes were presented as sarcoplasmic degeneration associated with loss of striation and increase in the interstitial cells with inflammatory cells infiltration together with Zenker's necrosis of some muscle bundle. The histopathological picture was improved markedly with FA that showed nearly normal architecture of muscle fibers only with mild degree of sarcoplasmic eosinophilia and limited sarcoplasmic degeneration within few bundles associated with normal nucleus in both muscles. This marked improvement in slides of combined Dex and FA treatment proved the protective antiatrophic effect of FA which appeared in preservation of muscle mass and cross sectional area.

\section{Conclusion:}

As previously detected in ferulic acid researches that prove its antioxidant and anti-inflammatory effects, our results support these effects. Furthermore, FA shows trophic effect on normal control skeletal muscles. Also, it antagonizes the myotrophic effect of dexamethasone in both fast glycolytic and slow oxidative muscle fibers. So, ferulic acid can be used as an adjuvant therapy with antiinflammatory corticosteroids to augment its therapeutic effect and reduce its myotrophic changes.

\section{Acknowledgements:}

We acknowledged our Physiology Department and Medical Experimental Research Center of Mansoura University for their significant assistance in the experimental portion of the research.

Author contribution: Abeer F. Mostafa and Shereen M. Samir designed and performed the research, analyze the data; also, wrote the paper.

Conflict of interest: The authors declare that there is no conflict of interest.

\section{References}

1- KINOSHITA H., MIYAKOSHI N., KASUKAWA Y., SAKAI S., SHIRAISHI A., SEGAWA T., OHUCHI K., FUJII M., SATO C. and YOICHI SHIMADA Y.: Effects of eldecalcitol on bone and skeletal muscles in glucocorticoid treated rats. J. Bone Miner Metab., 34 (2): 171-8. Doi: 10.1007/s00774-015-0664-4, 2016.

2- SCHAKMAN O., KALISTA S., BARBE C., LOUMAYE A. and THISSEN J.P.: Glucocorticoid-induced skeletal muscle atrophy. Int. J. Biochem. Cell Biol., 45: 2163-72, 2013.

3- LUCIA A., NOGALES-GADEA G., PEREZ M., MARTIN M.A., ANDREU A.L. and ARENAS J.: Mc Ardle disease: What do neurologists need to know? Nat. Clin. Pract. Neurol., 4: 568-77, 2008.

4- NOGALES-GADEA G., CONSUEGRA-GARCIA I., RUBIO J.C., ARENAS J., CUADROS M., CAMARA Y., TORRESTORRONTERAS J., FIUZA-LUCES C., LUCIA A., MARTIN M.A., GARCIA-ARUMI E. and ANDREU A.L.: A transcriptomic approach to search for novel phenotypic regulators in McArdle disease. PLoS One, 7 : e31718, 2012.

5- CASTILLERO E., ALAMDARI N., LECKER S.H. and HASSELGREN P.O.: Suppression of atrogin-1 and MuRF1 prevents dexamethasone-induced atrophy of cultured myotubes. Metabolism, 62: 1495-502, 2013.

6- SHIKATANI E.A., TRIFONOVA A., MANDEL E.R., LIU S.T., ROUDIER E., KRYLOVA A., SZIGIATO A., BEAUDRY J., RIDDELL M.C. and HAAS T.L.: Inhibition of proliferation, migration and proteolysis contribute to corticosterone-mediated inhibition of angiogenesis. PLoS One, 7: e46625, 2012.

7- GUPTA A. and GUPTA Y.: Glucocorticoid-induced myopathy: Pathophysiology, diagnosis, and treatment. Indian J. Endocrinol. Metab., 17 (5): 913-6. Doi: 10.4103/22308210.117215, 2013.

8- MATTILA P. and HELLSTRÖM J.: Phenolic acids in potatoes, vegetables, and some of their products. J. Food Comp. Anal., 20: 152-60, 2007. 
9- MATTILA P., HELLSTRÖM J. and TÖRRÖNEN R.: Phenolic acids in berries, fruits, and beverages. J. Agric. Food Chem., 54: 7193-9. PMID: 16968082, 2006.

10- SAKAI S., KAWAMATA H., KOGURE T., MANTANI N., TERASAWA K. and UMATAKE M.: Inhibitory effect of ferulic acid and isoferulic acid on the production of macrophage inflammatory protein-2 in response to respiratory syncytial virus infection in RAW264.7 cells. Mediators Inflamm., 8: 173-5. PMID:10704056, 1999.

11- KANSKI J., AKSENOVA M., STOYANOVA A. and BUTTERFIELD D.A.: Ferulic acid antioxidant protection against hydroxyl and peroxyl radical oxidation in synaptosomal and neuronal cell culture systems in vitro: Structure activity studies. J. Nutr. Biochem., 13: 273-81. PMID: 12015157, 2002.

12- BALASUBASHINI M.S., RUKKUMANI R., VISWANATHAN P. and MENON V.P.: Ferulic acid alleviates lipid peroxidation in diabetic rats. Phytother. Res., 18: 310-14. PMID: 15162367, 2004.

13- SRINIVASAN M., SUDHEER A.R., PILLAI K.R., KUMAR P.R., SUDHAKARAN P.R. and MENON V.P.: Influence of ferulic acid on y-radiation induced DNA damage, lipid peroxidation and antioxidant status in primary culture of isolated rat hepatocytes. Toxicology, 228: 249-58. PMID: 17049709, 2006.

14- KUMAR N. and PRUTHI V.: Potential applications of ferulic acid from natural sources. Biotechnol. Rep., 4: 86-93, 2014.

15- HIRABAYASHI T., OCHIAI H., SAKAI S., NAKAJIMA $\mathrm{K}$. and TERASAWA K.: Inhibitory effect of ferulic acid and isoferulic acid on murine interleukin- 8 production in response to influenza virus infections in vitro and in vivo. Planta. Med., 61: 221-6, 1995.

16- NAGASAKA R., CHOTIMARKORN C., SHAFIQUL I. M., HORI M., OZAKI H. and USHIO H.: Antiinflammatory effects of hydroxycinnamic acid derivatives. Biochem Biophys. Res. Commun., 358: 615-9, 2007.

17- SRI BALASUBASHINI M., RUKKUMANI R. and MENON V.P.: Protective effects of ferulic acid on hyperlipidemic diabetic rats. Acta. Diabetol., 40: 118-22, 2003.

18- ALAM M.A., SERNIA C. and BROWN L.: Ferulic acid improves cardiovascular and kidney structure and function in hypertensive rats. J. Cardiovasc. Pharmacol., 61: 2409, 2013.

19- MORI H., KAWABATA K., YOSHIMI N., TANAKA T., MURAKAMI T., OKADA T. and MURAI H.: Chemopreventive effects of ferulic acid on oral and rice germ on large bowel carcinogenesis. Anticancer. Res., 19: 37758, 1999.

20- BARONE E., CALABRESE V. and MANCUSO C.: Ferulic acid and its therapeutic potential as a hormetin for age-related diseases. Biogerontology, 10: 97-108, 2009.

21- TADA Y., TAYAMA K. and AOKI N.: Acute oral toxicity of ferulic acid, natural food additive, in rats. Ann. Rep. Tokyo Metr. Res. Lab. Public Health, 50: 311-3, 1999.

22- LIN F.H., LIN J.Y., GUPTA R.D., TOURNAS J.A., BURCH J.A., SELIM M.A., MONTEIRO-RIVIERE N.A., GRICHNIK J.M., ZIELINSKI J. and PINNELL S.R.: Ferulic acid stabilizes a solution of Vitamins $\mathrm{C}$ and $\mathrm{E}$ and doubles its photoprotection of skin. J. Investig. Dermatol., 125: 826-32, 2005.
23- MORIMOTO Y., KONDO Y., KATAOKA H., HONDA Y., KOZU R., SAKAMOTO J., NAKANO J., ORIGUCHI T., YOSHIMURA T. and OKITA M.: Heat treatment inhibits skeletal muscle atrophy of glucocorticoid-induced myopathy in rats. Physiol. Res., 64: 897-905, 2015.

24- YIN Y., QI F., SONG Z., ZHANG B. and TENG J.: Ferulic acid combined with astragaloside IV protects against vascular endothelial dysfunction in diabetic rats. BioScience Trends., 8 (4): 217-26. Doi: 10.5582/bst.2014. 01081, 2014.

25- KAMMOUN M., CASSAR-MALEK I., MEUNIER B and PICARD B.: A Simplified Immunohistochemical Classification of Skeletal Muscle Fibres in Mouse. Eur. J. Histochem., 15: 58 (2): 2254. Doi: 10.4081/ejh.2014. 2254,2014

26- CROES S.A. and VON BARTHELD C.S.: Measurement of Contractile Force of Skeletal and Extraocular Muscles: Effects of Blood Supply, Muscle Size and In Situ or In Vitro Preparation. J. Neurosci. Methods, 15 (1): 53-65. Doi: 10. 101 6/j.jneumeth.2007.06.024, 2007.

27- HAKIM C.H., LI D. and DUAN D.: Monitoring Murine Skeletal Muscle Function for Muscle Gene Therapy. Methods Mol. Biol., 709: 75-89. Doi: 10.1007/978-161737-982-6_5, 2011.

28- CHOMCZYNSKI P. and SACCHI N.: Single-step method of RNA isolation by acidguanidinium thiocyanate-phenolchloroform extraction. Anal. Biochem., 1162: 156-9, 1987.

29- RISSON V., MAZELIN L., ROCERI M., SANCHEZ H., MONCOLLIN V., CORNELOUP C., RICHARDBULTEAU H., VIGNAUD A., BAAS D., DEFOUR A., FREYSSENET D., TANTI J.F., LE-MARCHANDBRUSTEL Y., FERRIER B., CONJARD-DUPLANY A., ROMANINO K., BAUCHE S., HANTAI D., MUELLER M., KOZMA S.C., THOMAS G., RUEGG M.A., FERRY A., PENDE M., BIGARD X., KOULMANN N., SCHAEFFER L. and GANGLOFF Y.G.: Muscle inactivation of mTOR causes metabolic and dystrophin defects leading to severe myopathy. J. Cell Biol., 187: 859-74, 2009.

30- ROCHETTE L., LORIN J., ZELLER M., GUILLAND J.C., LORGIS L., COTTIN Y. and VERGELY C.: Nitric oxide synthase inhibition and oxidative stress in cardiovascular diseases: Possible therapeutic targets? Pharmacol. Ther., 140: 239-57, 2013.

31- PITOCCO D., TESAURO M., ALESSANDRO R., GHIRLANDA G. and CARDILLO C.: Oxidative stress in diabetes: Implications for vascular and other complications. Int. J. Mol. Sci., 14: 21525-50, 2013.

32- YIN Y., QI F., SONG Z., ZHANG B. and TENG J.: Ferulic acid combined with astragaloside IV protects against vascular endothelial dysfunction in diabetic rats BioScience Trends., 8 (4): 217-26. Doi: 10.5582/bst.2014. 01081, 2014.

33- HEINEMEIER K.M., OLESEN J.L., SCHJERLING, HADDAD F.H., LANGBERG H., BALDWIN K.M. and KJAER M.: Short-term strength training and the expression of myostatin and IGF-I isoforms in rat muscle and tendon: Differential effects of specific contraction types. J. Appl. Physiol., 102: 573-81, 2007.

34- SHIBAGUCHI T., MAEOKA T., YOSHIHARA T., NAITO H., GOTO K., YOSHIOKA T. and SUGIUR T.: Age- 
related changes in myostatin expression in rat skeletal muscles. J. Phys. Fitness Sports Med., 7 (4): 221-7. Doi: 10.7600/jpfsm.7.221, 2018.

35- McFARLANE C., PLUMMER E., THOMAS M., HENNEBRY A., ASHBY M., LING N., SMITH H., SHARMA M. and KAMBADUR R.: Myostatin induces cachexia by activating the ubiquitin proteolytic system through an NF-kappaB-independent, FoxO1- dependent mechanism. J. Cell Physiol., 209: 501-14. Doi: 10.1002/jcp.20757, 2006.

36- HAIDET A.M., RIZO L., HANDY C., UMAPATHI P., EAGLE A., SHILLING C., BOUE D., MARTIN P.T., SAHENK Z., MENDELL J.R. and KASPAR B.K.: Longterm enhancement of skeletal muscle mass and strength by single gene administration of myostatin inhibitors. Proc. Natl. Acad. Sci. USA, 105: 4318-22. Doi: 10.1073/ pnas.0709144105, 2008.

37- LeBRASSEUR N.K., SCHELHORN T.M., BERNARDO B.L., COSGROVE P.G., LORIA P.M. and BROWN T.A.: Myostatin inhibition enhances the effects of exercise on performance and metabolic outcomes in aged mice. $\mathrm{J}$.
Gerontol. A. Biol. Sci. Med. Sci., 64: 940-8. Doi: 10.1093/ gerona/glp068, 2009.

38- MURPHY K.T., KOOPMAN R., NAIM T., LEGER B., TRIEU J., IBEBUNJO C. and LYNCH G.S.: Antibodydirected myostatin inhibition in 21-mo-old mice reveals novel roles for myostatin signaling in skeletal muscle structure and function. FASEB J., 24: 4433-42. Doi: 10.1096/fj.10-159608, 2010.

39- GOLDSPINK G.: Gene expression in muscle in response to exercise. J. Muscle Res. Cell Motil., 24: 121-6, 2003.

40- LÓPEZ-HERRADÓ A., FUJIKAWA R., GÓMEZ-MARÍ M., STEDILE-LOVATEL J.P., MULERO F., ARDURA J.A., RUIZ P., MUÑ I., ESBRIT P., MAHÍLLOFERNÁNDEZ I. and ORTEGA-De MUES A.: Impact of Chiropractic Manipulation on Bone and Skeletal Muscle of Ovariectomized Rats. Calcif. Tissue Int., 101: 519-29. Doi 10.1007/s00223-017-0304-1, 2017.

41- MATHENY R.W. Jr., NINDL B.C. and ADAMO M.L.: Minireview: Mechano-growth factor: A putative product of IGF-I gene expression involved in tissue repair and regeneration. Endocrinology, 151: 865-75, 2010. 


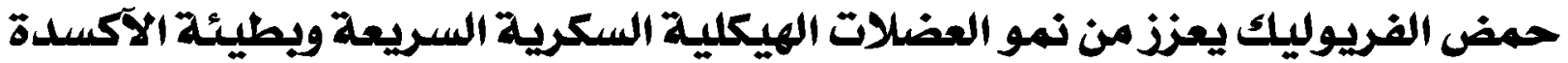

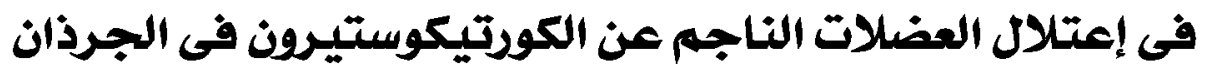

المقدمة: تعد الكورتوزينات من آكثر مضادات الإلتهاب إستخداما فى العديد من الآمراض، والكنها تؤدى إلى العديد من الآثار الجانبية

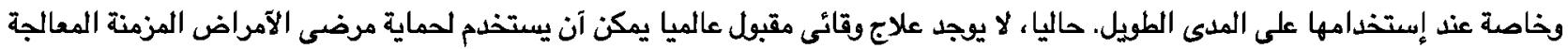
بالكوتينون لفترات زمنية طويلة.

الهدف من البحث: دراسة الدود المفيد المحتمل لحمض الفيريوليك، كمضاد طبيعى للاككسة والإلتهابات، فى منع ضمود العضدلات وتعزيز

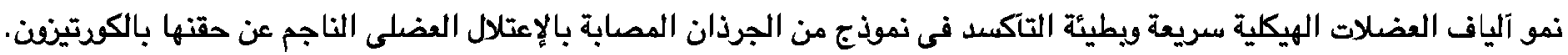

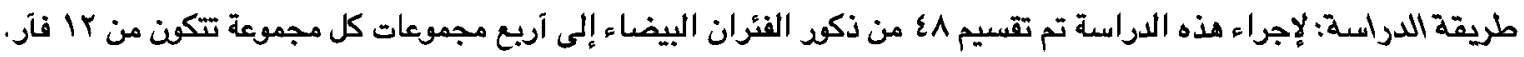


(إسبوعين).

• المجموعة الثانية: فئران هذه المجموعة تم إعطائها حمض الفريوليك (•مجم/كجم) عن طريق الفم مرة واحدة يوميا لمدة إسبوعين. • المجموعة الثالثة: حقنت هذه المجموعة بهرمون الكوتينون (دكساميثانفن، بمجم/كجم)، تم العقن تعت الجلد مرة واحدة يوميا لمدة إسبوعين.

• المجموعة الرابعة: آعطيت فئران هذه المجموعة آكلا من هرمون الكوتينين عن طريق الحقن بالإضافة إلى حمض الفريوليك عن طريق الفم بنفس الجرعات المستخدمة سابقا فى المجموعتين الثانية والثالثة.

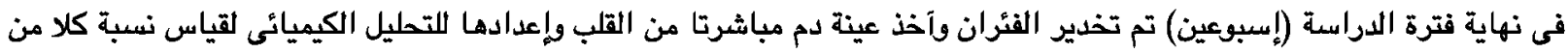

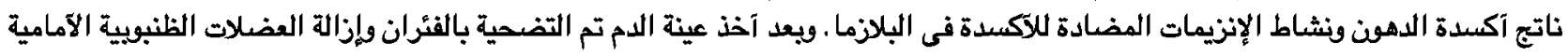

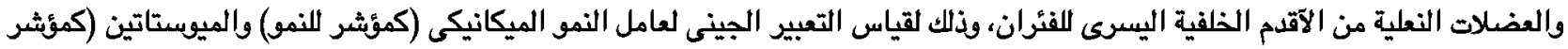

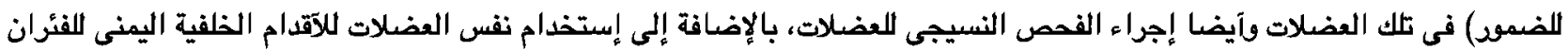

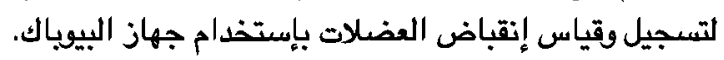

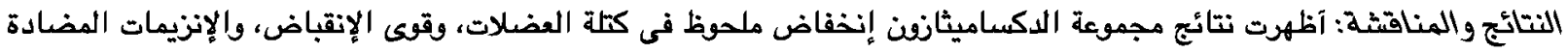

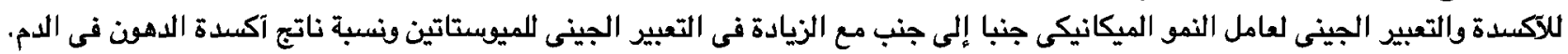

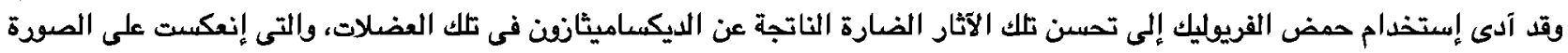
المكريسكوبية لنسيج العضلات وزيادة قدرة العضلات على الإنقباض مقارنتا بمجموعة الدكساميثازنف.

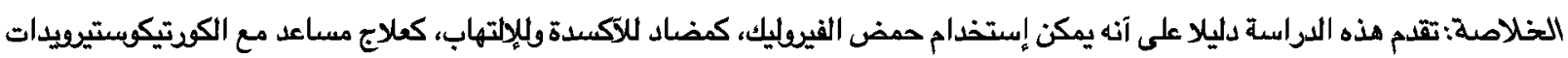

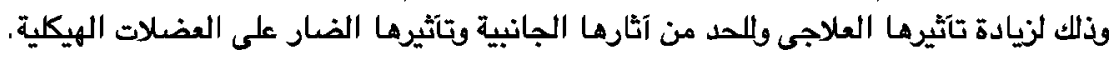

